\title{
Diet and cancer risk in Mediterranean countries: open issues
}

\author{
Carlo La Vecchia ${ }^{1,2, *}$ and Cristina Bosetti ${ }^{1}$ \\ ${ }^{1}$ Istituto di Ricerche Farmacologiche, Mario Negri, Milano, Italy: ${ }^{2}$ Istituto di Statistica Medica e Biometria, \\ Università di Milano, Milano, Italy
}

Submitted 20 April 2006: Accepted 10 0ctober 2006

\begin{abstract}
Objective: To analyse various aspects of the Mediterranean diet in relation to the risk of several common cancers in Italy.

Design: Data from a series of case-control studies conducted in northern Italy between 1983 and 2004 on over 20000 cases of several major cancers and 18000 controls.

Results: For most digestive tract cancers, the risk decreased with increasing vegetable and fruit consumption, with relative risks between 0.3 and 0.7 for the highest level of intake, and the population-attributable risks for low intake of vegetables and fruit ranged between 15 and 40\%. Less strong inverse relations were observed for other (epithelial) cancers, too. A number of micronutrients contained in vegetables and fruit showed an inverse relation with cancer risk. In particular, flavones, flavonols and resveratrol were inversely related to breast cancer risk. Olive oil, which is a typical aspect of the Mediterranean diet, has also been inversely related to cancers of the colorectum and breast, and mainly of the upper digestive and respiratory tract. Consumption of pizza, one of the most typical Italian foods, was related to a reduced risk of digestive tract cancers, although pizza may simply be an aspecific indicator of the Italian diet.

Conclusions: Adherence to the Mediterranean diet is a favourable indicator of the risk of several common epithelial cancers in Italy. A score summarising the major characteristics of the Mediterranean diet was related to a priori defined reduced risks of several digestive tract neoplasms by over $50 \%$.
\end{abstract}

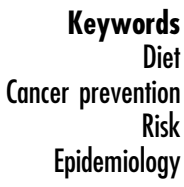

Mediterranean diet is a general term indicating a complex of dietary patterns which includes different components in various regions of the Mediterranean, but is generally characterised by frequent consumption of fruit and vegetables, pulses and fish, low consumption of meat and cheese, and (as a major common characteristic) olive oil for seasoning.

Several aspects of the Mediterranean diet have been related to a reduced risk not only of cardiovascular disease, but also of several cancers, and it has been suggested that up to $25 \%$ of colorectal, $15 \%$ of breast and $10 \%$ of prostate, pancreas and endometrial cancers could be prevented by shifting to a Mediterranean diet ${ }^{1}$.

In the present paper, we will review the main findings on various aspects of Mediterranean diet and cancer risk from an integrated series of multicentric case-control studies conducted in Italy. This included over 20000 cases of several major cancers and 18000 controls collected since the early 1980s.

\section{Vegetables and fruit}

In this series of case-control studies, vegetable intake was inversely related to the risk of several common epithelial cancers: the relative risks (RRs) for digestive tract neoplasms ranged between 0.3 and 0.7 for the highest compared with the lowest tertile of vegetable intake (Fig. 1). Less consistent inverse relations were observed for some hormone-related neoplasms, such as breast and ovary. Fruit was associated in particular to reduced RRs of cancers of the upper digestive tract, stomach and urinary tract. For digestive tract cancers, population-attributable risks for low intake of vegetables and fruit ranged between 15 and $40 \%{ }^{2}$. No material effect, however, was observed for fruit intake on neoplasms of the breast, the female genital tract or the prostate.

\section{Selected micronutrients}

The role of selected micronutrients contained in vegetables and fruit was also considered. Carotenoids, vitamin $\mathrm{E}$ and calcium showed an inverse relation with breast cancer risk ${ }^{3}$. More important, ascorbic acid, carotenoids and other antioxidant vitamins were consistently and inversely related not only to upper digestive and respiratory tract neoplasms ${ }^{4,5}$, but also to gastric cancer ${ }^{6}$. Likewise, tomato intake, and hence lycopene, was inversely related to several digestive tract neoplasms, but 


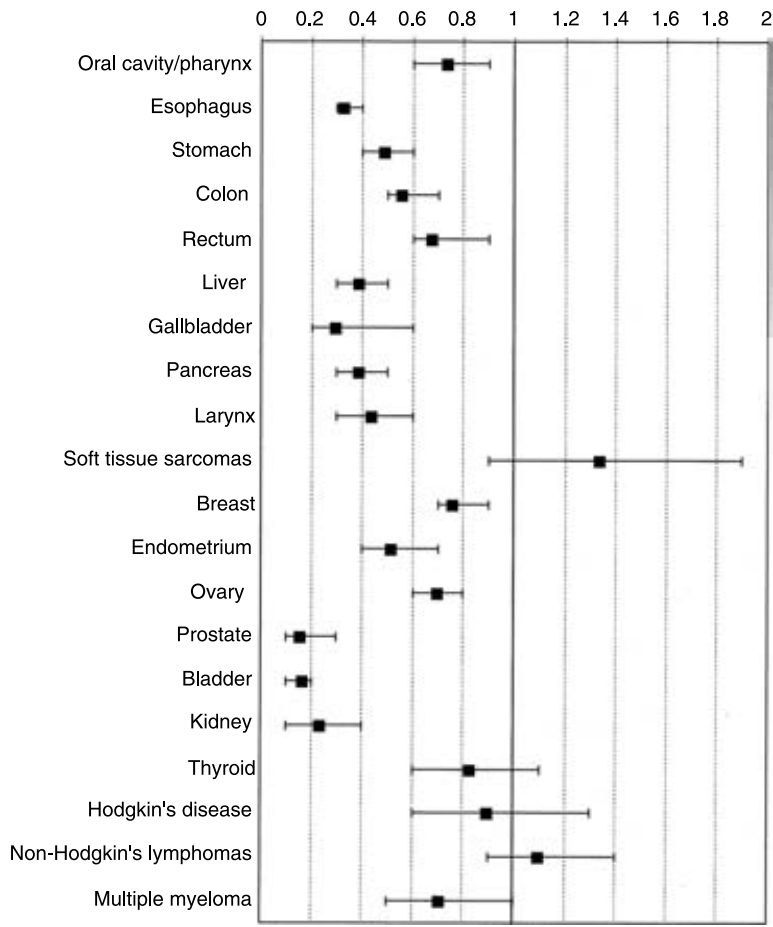

Fig. 1 RRs and $95 \% \mathrm{Cl}$ of selected cancers for the highest vs. the lowest levels of vegetable consumption. Italy, 1983-1997

not to breast, female genital tract and prostate cancers ${ }^{7,8}$. For colorectal cancer, there was an apparently synergistic effect of calcium, vitamins D, E and carotenoids, the RR reaching 0.46 in subjects reporting high calcium/vitamin D and high antioxidant intake, as compared with those reporting low intake of both groups of micronutrients?

Folate is a micronutrient of special interest in relation to cancer risk, following the identification of a number of single nucleotide polymorphisms of vitamin B-related metabolic genes that are involved in the process of carcinogenesis. Folate level is thought to affect cancer risk through its role in both methylation and nucleotide synthesis of $\mathrm{DNA}^{10}$. Alcohol consumption, which is frequent in Italy, may interfere with folate absorption and increase folate excretion by the kidney, therefore causing relative folate deficiency.

In our series of data, folate was inversely associated with all cancer sites considered ${ }^{4,11-15}$ (Fig. 2). The strongest associations emerged for upper aerodigestive tract neoplasms (RRs between 0.4 and 0.6 for the highest level of intake), rectal $(R R=0.6)$ and prostate $(R R=0.7)$ cancers. For some of these cancer sites (i.e. colorectum, breast and prostate), there was some indication of an interaction between folate and alcohol consumption, i.e. the inverse relation was more evident among drinkers.

\section{Flavonoids, resveratrol and breast cancer risk}

Flavonoids are polyphenols present in vegetables, fruit and beverages of plant origin, which have antioxidant,

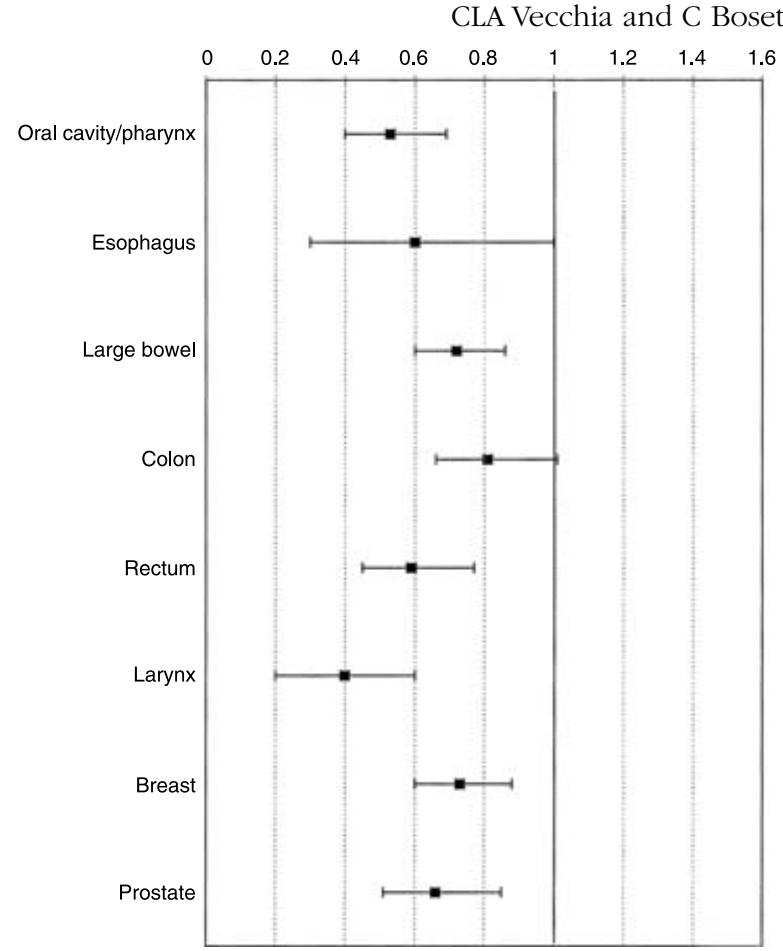

Fig. 2 RRs and $95 \% \mathrm{Cl}$ of selected cancers for the highest vs. the lowest levels of folate consumption. Italy, 1983-1997

antimitogenic and antiproliferative potential. They may have therefore a protective role in various chronic diseases, including selected neoplasms.

We have applied data on the flavonoid content of several foods and beverages on dietary information collected in the context of a case-control study of 820 women with breast cancer and 1548 controls, conducted in Greece $^{16}$. The RR for an increment of $0.5 \mathrm{mg}$ day $^{-1}$ of flavone was 0.87 . The association persisted after controlling for fruit and vegetable consumption or for other flavonoid intake. This inverse association is compatible with the reported inverse association of breast cancer with consumption of vegetables, particularly leafy vegetables.

A similar investigation was conducted in Italy. The study included 2569 women with incident histologically confirmed breast cancer and 2588 hospital controls ${ }^{17}$ After allowance for major potential confounding factors and energy intake, a reduced risk of breast cancer was found for increasing intake of flavones $(R R=0.81$, for the highest vs. the lowest quintiles) and flavonols ( $R R=0.80$, Table 1). No consistent association was found for other flavonoids.

We have also analysed the relation between dietary intake of resveratrol and breast cancer risk using data from a case-control study conducted between 1993 and 2003 in the Swiss Canton of Vaud on 369 cases and 602 controls $^{18}$. Compared with the lowest tertile of resveratrol intake, the multivariate RRs were 0.50 for the intermediate and 0.39 for the highest tertile, and the trend in risk was significant. 
Table 1 Flavonoids and breast cancer risk in Italy. Data from a multicentric study of 2569 cases and 2558 controls $^{17}$

\begin{tabular}{|c|c|c|c|c|c|c|c|c|}
\hline \multirow[b]{2}{*}{ Flavonoids } & \multirow[b]{2}{*}{ Median* } & \multicolumn{5}{|c|}{ Quintile of intake } & \multirow[b]{2}{*}{$\chi_{\text {trend }}^{2}$} & \multirow[b]{2}{*}{ OR \#\# continuous } \\
\hline & & $1 \dagger$ & 2 & 3 & 4 & 5 & & \\
\hline $\begin{array}{l}\text { Flavanones } \\
\text { Upper cut-point (mg) } \\
\text { OR\# } \\
95 \% \mathrm{Cl}\end{array}$ & 33.7 & $\begin{array}{c}11.5 \\
1.00\end{array}$ & $\begin{array}{c}29.1 \\
1.19 \\
(1.00-1.43)\end{array}$ & $\begin{array}{c}37.7 \\
1.11 \\
(0.92-1.33)\end{array}$ & $\begin{array}{c}62.2 \\
1.15 \\
(0.96-1.38)\end{array}$ & $\begin{array}{c}0.95 \\
(0.79-1.15)\end{array}$ & $\begin{array}{c}0.48 \\
(0.49)\end{array}$ & $\begin{array}{c}0.95 \\
(0.87-1.04)\end{array}$ \\
\hline $\begin{array}{l}\text { Flavan-3-ols } \\
\text { Upper cut-point (mg) } \\
\text { OR\# } \\
95 \% \mathrm{Cl}\end{array}$ & 36.4 & $\begin{array}{c}18.1 \\
1.00\end{array}$ & $\begin{array}{c}30.3 \\
0.98 \\
(0.82-1.18)\end{array}$ & $\begin{array}{c}44.1 \\
0.80 \\
(0.66-0.98)\end{array}$ & $\begin{array}{c}79.7 \\
1.01 \\
(0.83-1.23)\end{array}$ & $\begin{array}{c}0.86 \\
(0.71-1.05)\end{array}$ & $\begin{array}{c}1.28 \\
(0.26)\end{array}$ & $\begin{array}{c}0.93 \\
(0.87-0.99)\end{array}$ \\
\hline $\begin{array}{l}\text { Flavonols } \\
\text { Upper cut-point (mg) } \\
\text { OR\# } \\
95 \% \mathrm{Cl}\end{array}$ & 18.62 & $\begin{array}{c}12.6 \\
1.00\end{array}$ & $\begin{array}{c}16.4 \\
0.81 \\
(0.67-0.98)\end{array}$ & $\begin{array}{c}21.5 \\
1.00 \\
(0.83-1.21)\end{array}$ & $\begin{array}{c}29.9 \\
0.82 \\
(0.67-1.00)\end{array}$ & $\begin{array}{c}0.80 \\
(0.66-0.98)\end{array}$ & $\begin{array}{c}3.52 \\
(0.06)\end{array}$ & $\begin{array}{c}0.94 \\
(0.88-1.01)\end{array}$ \\
\hline $\begin{array}{l}\text { Flavones } \\
\text { Upper cut-point (mg) } \\
\text { OR\# } \\
95 \% \mathrm{Cl}\end{array}$ & 0.45 & $\begin{array}{l}0.2 \\
1.00\end{array}$ & $\begin{array}{c}0.3 \\
0.94 \\
(0.79-1.13)\end{array}$ & $\begin{array}{c}0.5 \\
0.97 \\
(0.81-1.17)\end{array}$ & $\begin{array}{c}0.6 \\
0.86 \\
(0.71-1.04)\end{array}$ & $\begin{array}{c}0.81 \\
(0.66-0.98)\end{array}$ & $\begin{array}{l}5.41 \\
(0.02)\end{array}$ & $\begin{array}{c}0.90 \\
(0.83-0.97)\end{array}$ \\
\hline $\begin{array}{l}\text { Anthocyanidins } \\
\text { Upper cut-point (mg) } \\
\text { OR\# } \\
95 \% \mathrm{Cl}\end{array}$ & 10.4 & $\begin{array}{l}3.7 \\
1.00\end{array}$ & $\begin{array}{c}7.9 \\
1.03 \\
(0.86-1.25)\end{array}$ & $\begin{array}{c}14.3 \\
1.16 \\
(0.95-1.40)\end{array}$ & $\begin{array}{c}20.5 \\
1.11 \\
(0.90-1.37)\end{array}$ & $\begin{array}{c}1.09 \\
(0.87-1.36)\end{array}$ & $\begin{array}{c}0.76 \\
(0.38)\end{array}$ & $\begin{array}{c}1.06 \\
(0.96-1.17)\end{array}$ \\
\hline $\begin{array}{l}\text { Isoflavones }(\mu g) \\
\text { Upper cut-point } \\
\text { OR\# } \\
95 \% \mathrm{Cl}\end{array}$ & 21.7 & $\begin{array}{c}13.4 \\
1.00\end{array}$ & $\begin{array}{c}19.0 \\
1.05 \\
(0.87-1.27)\end{array}$ & $\begin{array}{c}25.2 \\
1.00 \\
(0.83-1.22)\end{array}$ & $\begin{array}{c}34.7 \\
1.02 \\
(0.84-1.24)\end{array}$ & $\begin{array}{c}1.05 \\
(0.86-1.29)\end{array}$ & $\begin{array}{c}0.08 \\
(0.78)\end{array}$ & $\begin{array}{c}0.97 \\
(0.91-1.04)\end{array}$ \\
\hline
\end{tabular}

* Median intake among controls.

†Reference category.

‡Estimates from multiple logistic regression models including terms for age, study centre, education, parity, alcohol consumption and non-alcohol energy intake.

\# Odds ratio for a difference in intake equal to the difference between the upper cut-point of the fourth quintile and that of the first one.

An inverse association was observed for resveratrol from grapes $(R R=0.64$ and 0.55$)$, but not from wine (Table 2$)$.

The inverse relation of flavones and - to a lesser extentflavonols and resveratrol with breast cancer risk may, at least in part, explain the inverse relation between vegetable consumption and breast cancer risk in this population.

\section{Meat}

Among various aspects of diet which appear to influence cancer risk, red meat is of specific relevance. In our integrated series of studies from Italy, the multivariate RRs for the highest tertile of meat intake ( $\geq 7$ times per week) compared with the lowest one ( $\leq 3$ times per week) were 1.7 for stomach, 2.0 for colon, 1.9 for rectal, 1.6 for pancreas, 1.5 for bladder, 1.5 for endometrial and 1.3 for ovarian cancers. This points to (red) meat as another important factor (after vegetables and fruits) in the nutritional aetiology of human cancer ${ }^{19}$. This finding has repeatedly been observed for colorectal cancer and is of particular importance for Mediterranean populations, whose traditional diet did not include high intake of red meat, but who are now changing this aspect of dietary habits in an unfavourable way ${ }^{1}$.

Table 2 Resveratrol and breast cancer risk. Data from a study of 369 cases and 602 controls $^{18}$

\begin{tabular}{|c|c|c|c|c|c|c|c|}
\hline & \multicolumn{2}{|c|}{ First tertile* } & \multicolumn{2}{|c|}{ Second tertile } & \multicolumn{2}{|c|}{ Third tertile } & \multirow[b]{2}{*}{$\chi_{1}^{2}$ trend } \\
\hline & $\begin{array}{l}\text { Case: } \\
\text { controls }\end{array}$ & $\begin{array}{c}\text { OR } \\
(95 \% \mathrm{Cl})\end{array}$ & $\begin{array}{l}\text { Case: } \\
\text { controls }\end{array}$ & OR $(95 \% \mathrm{Cl})$ & Case:controls & OR $(95 \% \mathrm{Cl})$ & \\
\hline Total (wine and grapes) & 133:208 & 1.0 & $84: 191$ & $050(0.34-0.72)$ & $152: 203$ & $0.39(0.25-0.62)$ & $18.80(P<0.001)$ \\
\hline Wine, total & $184: 406$ & 1.0 & $69: 92$ & $1.05(0.18-8.25)$ & $116: 104$ & $1.60(0.28-9.28)$ & $1.35(P=0.25)$ \\
\hline Grapes & 168:213 & 1.0 & $79: 151$ & $0.64(0.44-0.93)$ & $122: 238$ & $0.55(0.39-0.76)$ & $12.79(P<0.001)$ \\
\hline
\end{tabular}

${ }^{*}$ Reference category: tertile of total resveratrol determined on controls distribution. The upper cut-points for the tertile of total resveratrol intake ( $\mu$ g per $100 \mathrm{~g} \mathrm{day}^{-1}$ ) ranged between 0.0 and 73.0 for the first tertile (lowest), 73.1 and 160.7 for the second tertile and $>160.7$ for the third tertile (highest); intake from wine was 0.0 for the first tertile, ranged between 0.1 and 176.8 for the second tertile and $>176.8$ for the third tertile; intake from grapes ranged between 0.0 and 72.2 for the first tertile, 72.3 and 126.4 for the second tertile and $>126.4$ for the third tertile. 


\section{Fish and n-3 fatty acids}

Fish intake (a major source of n-3 polyunsaturated fatty acids, PUFA) has been shown to be a favourable indicator for several common cancers ${ }^{20}$. In our dataset, first consumption was associated with a decreased risk for several digestive tract cancers ${ }^{20}$. The RRs were consistently below unity for digestive tract cancers (RR between 0.7 and 0.8), as well as for gallbladder and laryngeal cancers. Inverse trends in risk were also observed for breast and female genital tract cancers, but not for bladder, urinary tract or lymphoid neoplasms.

The continuous RRs for an increase of $1 \mathrm{~g} \mathrm{week}^{-1}$ of $\mathrm{n}-3$ PUFAs are reported in Fig. 3. The RRs were below unity for all cancers considered, except prostate: 0.7 for oral/ pharyngeal and oesophageal cancers, and 0.9 for colon, rectal, breast and ovarian cancers ${ }^{21}$. As n-3 PUFAs are incorporated into cell membranes and influence several biological responses ${ }^{22}$, multiple mechanisms may be involved in their activity. These include suppression of neoplastic transformation, cell growth inhibition, influence on the immune system and inflammation ${ }^{23,24}$, enhanced apoptosis and antiangiogenesis ${ }^{25}$.

The data from this integrated network of studies confirm therefore that fish, and consequently n-3 PUFA consumption, is a favourable indicator of the risk of several common cancers, mainly those of the digestive tract. The results are less clear for breast and prostate cancers. The inverse relation between fish/n-3 PUFAs and cancers of the digestive tract was not explained by sociodemographic

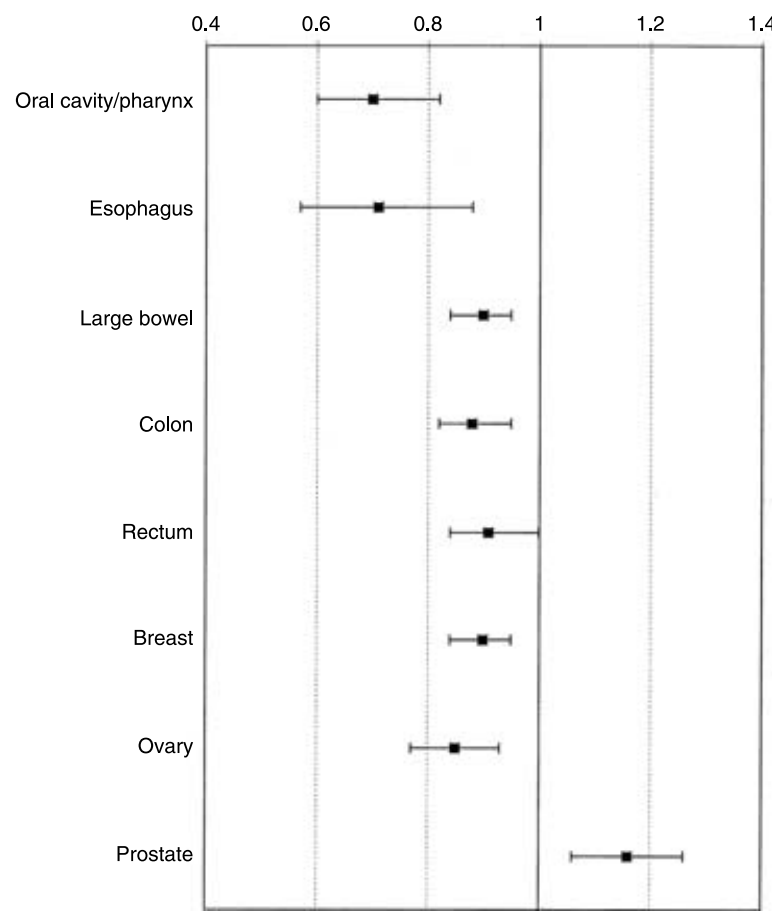

Fig. 3 RRs and $95 \% \mathrm{Cl}$ of selected cancers for an increase of $1 \mathrm{~g} \mathrm{week}^{-1}$ of $\mathrm{n}-3$ polyunsaturated fatty acids (PUFA). Italy, 1992-2004 factors, total energy intake and selected other covariates. Together with the favourable effect of fish and n-3 PUFA intake on the cardiovascular system ${ }^{26,27}$, the results from these data indicate that fish is a preferable substitute for meat intake in our diet ${ }^{19}$.

\section{Fibres, whole and refined cereals}

In the Italian network of case-control studies, the RRs for the highest consumption level of whole-grain foods were 0.2-0.3 for upper digestive and respiratory tract neoplasms, 0.5 for stomach, colon and gallbladder, 0.7 for rectum, 0.6 for liver, 0.8 for pancreas and prostate, 0.9 for breast and endometrium, 0.6 for ovary, 0.4 for bladder and kidney and around 0.5 for lymphomas and myelomas. Thus, in this population, high frequency of whole-grain food intake is an indicator of reduced cancer risk ${ }^{28}$.

With reference to fibres and colorectal carcinogenesis, in our data ${ }^{29}$ from an area with intermediate colorectal cancer incidence and mortality on a European level ${ }^{30}$, the RR of colon and rectal cancers was below unity for most types of fibres, and no appreciable differences emerged between the two sites. The RRs for colorectal cancer for an increment equal to the difference between the 80th and the 20th percentiles were 0.68 for total fibres, 0.67 for soluble non-cellulose polysaccharides (NCP), 0.71 for total insoluble fibre, 0.67 for cellulose, 0.82 for insoluble NCP and 0.88 for lignin. When fibre was classified according to the source, the RR was 0.75 for vegetable fibre, 0.85 for fruit fibre, but 1.09 for cereal fibre.

In contrast, refined grain intake was associated with an increased risk of stomach, colorectal, breast, upper digestive sites and thyroid cancers in studies conducted in Mediterranean populations ${ }^{31,32}$. Glycaemic index (GI) and glycaemic load (GL) are indicators of the rate of adsorption of carbohydrates, and hence measures of insulin demand, and have been suggested to be relevant factors in gastric, colorectal, breast, female genital tract and prostatic carcinogenesis. The points to a potential role of insulin and hence insulin-like growth factors (IGFs) in cancer promotion $^{31-39}$. The RRs for the highest levels of GI/GL vs. the lowest ones were around 2 for various cancers considered.

Whole-grain foods should therefore replace refined cereal ones. This is of specific relevance in countries like Italy, where white bread and pasta are major components of the diet.

\section{Olive oil and fats}

The possible relation between total fats, and specific types of fats, and cancer risk remains a major open issue. In large studies from Italy, isocaloric substitution of 5\% of total calories as saturated fats by unsaturated ones was associated with reductions in breast $(R R=0.67)$ and colorectal $(R R=0.78)$ cancer risk. Replacement of 
complex carbohydrates by unsaturated fats was associated with similar risk reductions. Part of the benefit for monounsaturated and polyunsaturated fats in the Mediterranean diet may be due to the positive correlation between (olive) oil and vegetable intake ${ }^{31}$. It seems, therefore, that substituting olive oil for other seasoning fats has favourable effects on the risk of breast ${ }^{31,40-43}$ and colorectal $^{44}$ cancers, as well as upper digestive tract neoplasms, with RRs for the highest consumption level of olive oil of 0.7 for oral/pharyngeal ${ }^{42}$ and laryngeal neoplasms ${ }^{46}$, and of 0.4 for oesophageal ${ }^{47}$ cancer.

Thus, neoplasms of the upper digestive and respiratory tract appear to be specifically and favourably influenced by olive oil. Frequent consumption of butter and other saturated fats, in contrast, was directly related to the risk of these neoplasms ${ }^{44-45}$.

\section{Pizza as an indicator of Mediterranean diet on cancer risk}

Pizza is one of the most typical and representative foods of the Italian diet. An inverse association was found between regular pizza consumption $(\geq 1$ portion of pizza per week) and the risk of cancers of the digestive tract ${ }^{48}$, with RRs of 0.66 for oral and pharyngeal cancers, 0.41 for oesophageal, 0.82 for laryngeal, 0.74 for colon and 0.93 for rectal cancers. The RRs for most cancers considered, and the corresponding trends in risk, were significant. However, pizza was not associated with the risk of sex hormone-related cancers, such as breast, ovarian and prostate cancers ${ }^{49}$. The favourable influence of pizza on the risk of several digestive tract neoplasms may be related to tomatoes or olive oil, which have been inversely related to the risk of the cancers considered. However, evaluating the biological effect of specific components of pizza remains difficult, and pizza may simply represent a general and aspecific indicator of a favourable Mediterranean diet.

\section{A Mediterranean diet score}

A simple and intuitive score ${ }^{50}$, summarising eight of the major characteristics of the Mediterranean diet, i.e. high consumption of cereals, legumes, fruit, vegetables, low consumption of meat, milk or dairy products, high monounsaturated/saturated fat ratio and moderate alcohol intake, was used to define a dietary pattern reflecting favourable aspects of diet. The relation between this $a$ priori defined nutritional pattern and the risk of cancers of the upper aerodigestive tract has been evaluated using data from three case-control studies conducted in Italy. For all cancers considered, a significant reduced risk was found for increasing levels of the Mediterranean score: the multivariate RRs for subjects with $\geq 6$ Mediterranean characteristics, compared with those with $<3$, were 0.40 for oral and pharyngeal, 0.26 for oesophageal and 0.23 for laryngeal cancers.

This provides therefore additional evidence that the combination of various food items reflecting the Mediterranean diet favourably affects the risk of several common cancers ${ }^{51}$.

\section{Acknowledgements}

Ms Ivana Garimoldi provided editorial assistance. This work was conducted with the contribution of the Italian Association for Cancer Research, the Italian League against Cancer and the Italian Ministry of Education and Research (COFIN 2005).

\section{References}

1 Trichopoulou A, Lagiou P, Kuper H, Trichoupulos D. Cancer and Mediterranean dietary traditions. Cancer Epidemiology, Biomarkers \& Prevention 2000; 9: 869-73.

2 La Vecchia C, Chatenoud L, Franceschi S, Soler M, Parazzini F, Negri E. Vegetables and fruit and human cancer: update of an Italian study. International Journal of Cancer 1999; 82: $151-2$.

3 Negri E, La Vecchia C, Franceschi S, D'Avanzo B, Talamini R, Parpinel $\mathrm{M}$, et al. Intake of selected micronutrients and the risk of breast cancer. International Journal of Cancer 1996; 65: $140-4$.

4 Bidoli E, Bosetti C, La Vecchia C, Levi F, Parpinel M, Talamini R, et al. Micronutrients and laryngeal cancer risk in Italy and Switzerland: a case-control study. Cancer Causes Control 2003; 14: $477-84$.

5 Negri E, Franceschi S, Bosetti C, Levi F, Conti E, Parpinel M, et al. Selected micronutrients and oral and pharyngeal cancer. International Journal of Cancer 2000; 86: 122-7.

6 La Vecchia C, Ferraroni M, D'Avanzo B, Decarli A, Franceschi S. Selected micronutrient intake and the risk of gastric cancer. Cancer Epidemiology, Biomarkers \& Prevention 1994; 3: 393-8.

7 La Vecchia C. Tomatoes, lycopene intake, and digestive tract and female hormone-related neoplasms. Experimental Biology and Medicine (Maywood) 2002; 227: 860-3.

8 Bosetti C, Talamini R, Montella M, Negri E, Conti E, Franceschi S, et al. Retinol, carotenoids and the risk of prostate cancer: a case-control study from Italy. International Journal of Cancer 2004; 112: 689-92.

9 La Vecchia C, Braga C, Negri E, Franceschi S, Russo A, Conti E, et al. Intake of selected micronutrients and the risk of colorectal cancer. International Journal of Cancer 1997; 73: 525-30.

10 Duthie SJ. Folic acid deficiency and cancer: mechanisms of DNA instability. British Medical Bulletin 1999; 55: 578-92.

11 Pelucchi C, Talamini R, Negri E, Levi F, Conti E, Franceschi S, et al. Folate intake and risk of oral and pharyngeal cancer. Annals of Oncology 2003; 14: 1677-81.

12 Franceschi S, Bidoli E, Negri E, Zambon P, Talamini R, Ruol A, et al. Role of macronutrients, vitamins and minerals in the aetiology of squamous-cell carcinoma of the oesophagus. International Journal of Cancer 2000; 86: 626-31.

13 La Vecchia C, Negri E, Pelucchi C, Franceschi S. Dietary folate and colorectal cancer. International Journal of Cancer 2002; 102: 545-7.

14 Negri E, La Vecchia C, Franceschi S. Dietary folate consumption and breast cancer risk (reply to). Journal of the National Cancer Institute 2000; 92: 1270-1. 
15 Pelucchi C, Galeone C, Talamini R, Negri E, Parpinel M, Franceschi S, et al. Dietary folate and risk of prostate cancer in Italy. Cancer Epidemiology, Biomarkers \& Prevention 2005; 14: 944-8.

16 Peterson J, Lagiou P, Samoli E, Lagiou A, Katsouyanni K, La Vecchia C, et al. Flavonoid intake and breast cancer risk: a case-control study in Greece. British Journal of Cancer 2003; 89: 1255-9.

17 Bosetti C, Spertini L, Parpinel M, Gnagnarella P, Lagiou P, Negri E, et al. Flavonoids and breast cancer risk in Italy. Cancer Epidemiology, Biomarkers \& Prevention 2005; 14: $805-8$.

18 Levi F, Pasche C, Lucchini F, Ghidoni R, Ferraroni M, La Vecchia C. Resveratrol and breast cancer risk. European Journal of Cancer Prevention 2005; 14: 139-42.

19 Tavani A, La Vecchia C, Gallus S, Lagiou P, Trichopoulos D, Levi F, et al. Red meat intake and cancer risk: a study in Italy. International Journal of Cancer 2000; 86: 425-8.

20 Fernandez E, Chatenoud L, La Vecchia C, Negri E, Franceschi S. Fish consumption and cancer risk. The American Journal of Clinical Nutrition 1999; 70: 85-90.

21 Tavani A, Pelucchi C, Parpinel M, Negri E, Franceschi S, Levi F, et al. N-3 Polyunsaturated fatty acid intake and cancer risk in Italy and Switzerland. International Journal of Cancer 2003; 105: 113-6

22 Alexander JW. Immunonutrition: the role of omega-3 fatty acids. Nutrition 1998; 14: 627-33.

23 Grimble RF. Nutritional modulation of immune function. The Proceedings of the Nutrition Society 2001; 60: 389-97.

24 Grant WB. Fish consumption, cancer, and Alzheimer disease. The American Journal of Clinical Nutrition 2000; 71: 599-603.

25 Rose DP, Connolly JM. Omega-3 fatty acids as cancer chemopreventive agents. Pharmacology \& Therapeutics 1999; 83: 217-44.

26 Marckmann P, Grønbaek M. Fish consumption and coronary heart disease mortality: a systematic review of prospective cohort studies. European Journal of Clinical Nutrition 1999; 53: 585-90.

27 GISSI-Prevenzione Investigators (Gruppo Italiano per lo Studio della Sopravvivenza nell'Infarto Miocardico). Dietary supplementation with $\mathrm{n}-3$ polyunsaturated fatty acids and vitamin $\mathrm{E}$ after myocardial infarction: results of the GISSIprevenzione trial. Lancet 1999; 354: 447-55.

28 Chatenoud L, Tavani A, La Vecchia C, Jacobs DR Jr, Negri E, Levi $\mathrm{F}$, et al. Whole grain food intake and cancer risk. International Journal of Cancer 1998; 77: 24-8.

29 Negri E, Franceschi S, Parpinel M, La Vecchia C. Fibre intake and risk of colorectal cancer. Cancer Epidemiology, Biomarkers \& Prevention 1998; 7: 667-71.

30 Fernandez E, La Vecchia C, Gonzalez JR, Lucchini F, Negri E, Levi F. Converging patterns of colorectal cancer mortality in Europe. European Journal of Cancer 2005; 41: 430-7.

31 Franceschi S, Russo A, La Vecchia C. Carbohydrates, fat and cancer of the breast and colon-rectum. Journal of Epidemiology and Biostatistics 1998; 3: 217-8.

32 Chatenoud L, La Vecchia C, Franceschi S, Tavani A, Jacobs DR $\mathrm{Jr}$, Parpinel MT, et al. Refined-cereal intake and risk of selected cancers in Italy. The American Journal of Clinical Nutrition 1999; 70: 1107-10.

33 Franceschi S, Dal Maso L, Augustin L, Negri E, Parpinel M, Boyle $\mathrm{P}$, et al. Dietary glycaemic load and colorectal cancer risk. Annals of Oncology 2001; 12: 173-8.
34 Augustin LS, Dal Maso L, La Vecchia C, Parpinel M, Negri E, Vaccarella S, et al. Dietary glycemic index and glycemic load, and breast cancer risk: a case-control study. Annals of Oncology 2001; 12: 1533-8.

35 Augustin LS, Gallus S, Negri E, La Vecchia C. Glycemic index, glycemic load and risk of gastric cancer. Annals of Oncology 2004; 15: 581-4.

36 Augustin LS, Galeone C, Dal Maso L, Pelucchi C, Ramazzotti V, Jenkins DJ, et al. Glycemic index, glycemic load and the risk of prostate cancer. International Journal of Cancer 2004; 112: $446-50$.

37 Augustin LS, Polesel J, Bosetti C, Kendall CW, La Vecchia C, Parpinel M, et al. Dietary glycemic index, glycemic load and ovarian cancer risk: a case-control study in Italy. Annals of Oncology 2003; 14: 78-84.

38 Augustin LS, Gallus S, Franceschi S, Negri E, Jenkins DJ, Kendall CW, et al. Glycemic index and load and risk of upper aero-digestive tract neoplasms (Italy). Cancer Causes Control 2003; 14: 657-62.

39 Augustin LS, Gallus S, Bosetti C, Levi F, Negri E, Franceschi S, et al. Glycemic index and glycemic load in endometrial cancer. International Journal of Cancer 2003; 105: 404-7.

40 La Vecchia C, Negri E, Franceschi S, Decarli A, Giacosa A, Lipworth L. Olive oil, other dietary fats, and the risk of breast cancer (Italy). Cancer Causes Control 1995; 6: 545-50.

41 Prieto-Ramos F, Serra-Majem L, La Vecchia C, Ramon JM, Tresserras R, Salieras L. Mortality trends and past and current dietary factors of breast cancer in Spain. European Journal of Epidemiology 1996; 12: 141-8.

42 Trichopoulou A. Olive oil and breast cancer. Cancer Causes Control 1995; 6: 545-50

43 Bosetti C, Micelotta S, Dal Maso L, Talamini R, Montella M, Negri E, et al. Food groups and risk of prostate cancer in Italy. International Journal of Cancer 2004; 110: 424-8.

44 Braga C, La Vecchia C, Franceschi S, Negri E, Parpinel M, Decarli A, et al. Olive oil, other seasoning fats, and the risk of colorectal carcinoma. Cancer 1998; 82: 448-53.

45 Franceschi S, Favero A, Conti E, Talamini R, Volpe R, Negri E, et al. Food groups, oils and butter and cancer of the oral cavity and pharynx. British Journal of Cancer 1999; 80: 614-20.

46 Bosetti C, La Vecchia C, Talamini R, Negri E, Levi F, Dal Maso L, et al. Food groups and laryngeal cancer risk: a case-control study from Italy and Switzerland. International Journal of Cancer 2002; 100: 355-60.

47 Bosetti C, La Vecchia C, Talamini R, Simonato L, Zambon P, Negri E, et al. Food groups and risk of squamous cell esophagel cancer in Northern Italy. International Journal of Cancer 2000; 87: 289-94.

48 Gallus S, Bosetti C, Negri E, Talamini R, Montella M, Conti E, et al. Does pizza protect against cancer? British Journal of Cancer 2003; 107: 283-4.

49 Gallus S, Talamini R, Bosetti C, Negri E, Montella M, Franceschi S, et al. Pizza consumption and the risk of breast, ovarian and prostate cancer. European Journal of Cancer Prevention 2006; 15: 74-6.

50 Bosetti C, Gallus S, Trichopoulou A, Talamini R, Franceschi S, Negri E, et al. Influence of the mediterranean diet on the risk of cancers of the upper aerodigestive tract. Cancer Epidemiology, Biomarkers \& Prevention 2003; 12: 1091-4.

51 Gallus S, Bosetti C, La Vecchia C. Mediterranean diet and cancer risk. European Journal of Cancer Prevention 2004; 13: $447-52$ 